\title{
ESSAY
}

Invited article

DOI: http://dx.doi.org/10.1590/So034-759020150109

\section{THE BEHAVIORAL PARADIGM SHIFT}

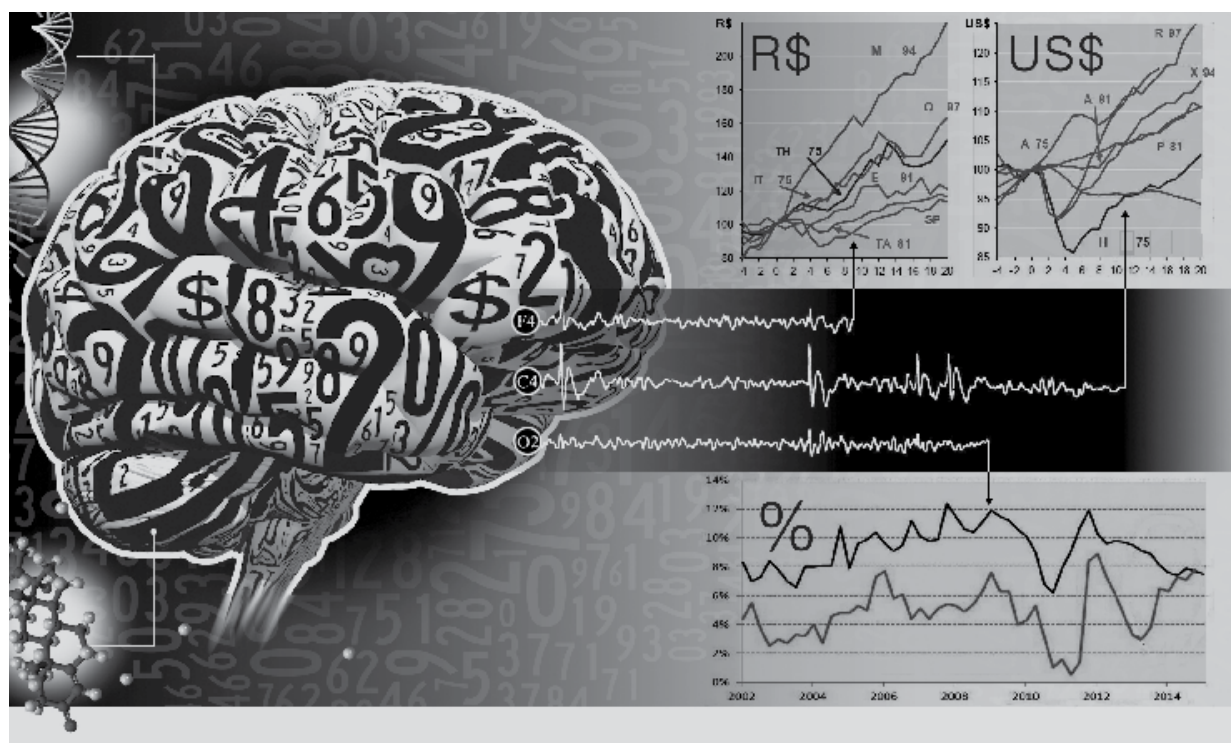

In the last half decade, academic finance has experienced two revolutions, one neoclassical and one behavioral, which were jointly recognized in the awarding of the 2013 Nobel Prize in economics. Before 1960, academic finance was organized around a loose collection of anecdotes, puzzles, and investment philosophies. The neoclassical revolution changed all of this by importing the structure and rigor of rationality-based principles of microeconomics into finance. Three Nobel Prizes recognized its main contributors. The first, in 1990, was jointly awarded to Harry Markowitz for mean-variance portfolio theory, to Merton Miller for corporate finance, and to William Sharpe for the capital asset pricing model (CAPM). The second prize, in 1997, was shared by Myron-Scholes and Robert Merton for developing the Black-Scholes-Merton option pricing formula. Unfortunately, Fischer Black who co-developed the formula, died in 1995. The third prize, in 2013, was awarded to three economists, two of whom contributed to the neoclassical revolution - Eugene Fama, for his seminal work on market efficiency, and Lars Peter Hansen for his seminal work on asset pricing theory.

The behavioral revolution imported ideas from behavioral psychology into finance, and replaced the rationality postulate with a more realistic alternative. Two of its main contributors were recognized with Nobel prizes. The first, in 2002, was awarded to Daniel Kahneman who shared the award with experimental economist Vernon Smith. The Nobel selection committee recognized Kahneman for his work with fellow psychologist Amos Tversky who died in 1996. The second prize, in 2013, was awarded to Robert Shiller for his work on asset pricing. Of course, this prize was shared by Shiller, Fama, and Hansen.

Both of these revolutions created great intellectual value. The neoclassical revolution

\section{HERSH SHEFRIN}

hshefrin@scu.edu

Professor at Santa Clara University, Leavey School of Business - Santa Clara - California, United States of America provided a first pass at introducing structure and rigor into the way academics think about financial issues. The behavioral revolution has provided a second pass at modifying this structure to reflect the fact that human beings are not perfectly rational, but are instead imperfectly rational. Behavioral finance focuses on the structure and implications of people's imperfect attempts to match means and ends when making financial decisions. 
In this second, behavioral, pass at finance, behaviorists are modifying every nook and cranny of the discipline. Mean-variance portfolio theory has its counterpart in behavioral portfolio theory. Corporate finance has its counterpart in behavioral corporate finance. The CAPM, which neoclassical asset pricing theorists such as Hansen generalized to pricing kernel theory, has its counterpart in behavioral pricing kernel theory; a special case is the behavioral Black-Scholes option pricing formula. Finally, the concept of efficient markets based upon the idea of arbitrage has its counterpart in inefficient markets based upon the idea that there are limits to arbitrage.

The behavioral revolution in finance and economics came fast on the heels of a similar behavioral revolution in psychology which gave us coherent frameworks to study how people make choices among risky prospects, how they rely on heuristics to form judgments, and how their imperfections leave them vulnerable to particular biases. The set of psychological frameworks and concepts from which behavioral economists draw includes prospect theory, SP/A theory, regret theory, change of process theory, excessive optimism, overconfidence, confirmation bias, anchoring-and-adjustment bias, illusion of control, representativeness, and the affect heuristic. Behavioral economists have been applying these frameworks and concepts to investigate issues across the entire landscape of finance.

In the remainder of these introductory remarks, I will offer a short personal perspective on how these developments from psychology impact aspects of finance, effectively my impressions of how the behavioral approach adds insights and value to the major subfields of finance: portfolio theory, asset pricing, and corporate finance.

Mean-variance theory tells us how investors can choose portfolios in which they optimally balance expected return against risk. Amazingly, in 1952 when Markowitz was developing mean-variance portfolio theory, he was also laying the groundwork for behavioral portfolio theory. In consecutive months he published two seminal papers, one neoclassical and the other behavioral. Kahneman and Tversky built prospect theory with Markowitz's behavioral piece constituting one of its core elements. Psychologist Lola Lopes also built SP/A theory with Markowitz's behavioral insights as a core element.

Prospect theory, applied to portfolio selection, tells us that investors will think about their portfolios as a collection of separate components (called mental accounts), rather than as a single integrated entity. Kahneman and Tversky told us that this lack of integration will make people vulnerable to making choices that violate first order stochastic dominance, meaning they will act as if they throw away money.

A key aspect of the explanation for why investors behave in this fashion is that they evaluate these components in terms of gains and losses, rather than net asset position. Moreover, they exhibit loss aversion in the sense of experiencing losses more acutely than gains. Loss aversion will induce people to be risk averse when facing situations in which they might experience gains if fortunate, but might also experience losses if unfortunate. However, at the same time, people will be averse to sure losses, and prone to exhibiting risk-seeking behavior when dealing with the prospect of a realized loss. Among Kahneman and Tversky's key lessons is the fourfold pattern in which people's risk appetite is circumstance dependent. When outcome probabilities are in the midrange, the average person is risk averse in the domain of gains and risk seeking in the domain of losses. When outcome probabilities of extreme events are small, the average person is risk seeking in the domain of gains and risk averse in the domain of losses.

The insights offered by prospect theory motivated Meir Statman and me to introduce "the disposition effect" into finance literature. The disposition effect holds that investors are predisposed to sell winners too quickly and hold losers too long, except in the month of December when the disposition will either weaken or reverse. Prospect theory was our starting point; however we pointed out that explaining the disposition effect required other psychological elements such as regret and self-control.

Statman and I developed the psychological underpinnings for the disposition effect against the results of a major study of individual investors by Lease, Lewellen, and Schlarbaurm who found evidence of disposition effect behavior, but argued that it did not stem from psychological sources. Several years later, Terry Odean built a rich database of U.S. individual investors and tested the main hypotheses Meir and I had developed. Subsequently, the disposition effect has become one of the most studied features of investor behavior. Researchers have investigated the disposition effect in different countries, different time periods, and different markets. They have also extended the analysis to professional investors, and studied its impact on asset prices.

The work of Lease, Lewellen, and Schlarbaum told us that investors trade too much, and that the portfolios of those who trade the most, the so-called "high rollers", experience the worst performance. Using transaction data that was more recent and more extensive, Brad Barber and Terry Odean documented the degree to which turnover hurts performance, and attributed excessive trading to overconfidence. Lease, Lewellen, and Schlarbaum also reported that high roll- 
ers are overly prone to focus on short-term capital gains and use technical analysis, and in recent work with Arvid Hoffmann, which uses data from Dutch investors, we find that this continues to be so.

In the last decade, research has shown that entertainment, gambling, and thrill seeking are important aspects in portfolio decisions, not just risk and expected returns. Markowitz's behavioral work dealt with people's tendency to hold both very safe and very risky securities simultaneously, a pattern that attracted the attention of psychologists Kahneman, Tversky, and Lopes, and which subsequently made its way back into finance. The "behavioral portfolio theory" put forward by Meir Statman and me emphasizes that investors build layered portfolios to provide both downside protection and upside potential. Alok Kumar documents the degree to which investors overweight "lottery stocks" in their portfolios: Lottery stocks are stocks that share some of the key traits exhibited by lotteries.

The 2013 Economics Nobel has highlighted the difference in neoclassical and behavioral perspectives about asset pricing. Fama tells us that it is not possible to distinguish whether asset prices are fully rational or whether they reflect behavioral biases instead. Shiller tells us that some asset prices are associated with pricing bubbles, and notes that he called both the dot.com bubble of the 1990 s and the real estate bubble underlying the global financial crisis that erupted in 2008.

The financial crisis spurred legislation to establish new regulatory practices. Although Statman and I have been writing about the behavioral dimension of financial market regulation since 1992, this is an area that although ripe for study has not proven to be especially popular among academics.

Over the years, Statman and I have written about asset pricing issues, both together and separately. We point out that having data on investors' expectations of returns, meaning ex ante judgments, as opposed to relying on ex post realized returns, can serve to distinguish whether or not prices are fully rational. This statement applies both to the cross-section of security returns and to the time series. In respect to the cross-section, Statman points out that investors' need for value expressiveness, which applies for example to socially responsible companies, will be manifest in their portfolio choices and also in the factor structure that explains returns.

My work has emphasized the importance of building behavioral pricing kernel models. These models extend the neoclassical models to incorporate sentiment, and in so doing generate a set of results about the impact of sentiment on the pricing of bonds, stocks, and all manner of derivatives. This approach emphasizes the importance of investor heterogeneity, and focuses on the manner in which markets aggregate the judgments of heterogeneous investors. One of the main theoretical results is a decomposition theorem establishing how the pricing kernel decomposes into a neoclassical component and sentiment. In recent co-authored work with Giovanni Barone-Adesi and Loriano Mancini, we apply this theorem to estimate sentiment, which we find to be closely linked to independent measures of sentiment such as the Baker-Wurgler sentiment variable SENT and Shiller's crash confidence index.

In 2000, I introduced the term "behavioral corporate finance" into finance literature. Before 2000, there were scattered applications of behavioral ideas to issues in corporate finance, but no general framework for understanding how behavioral elements impact the entire subfield. Now, almost fifteen years later, there is a rich literature documenting how psychological elements impact valuation, capital budgeting, capital structure, corporate incentive structures, merger and acquisition activity, and corporate governance. Although some of these issues pertain to the impact of psychological imperfections on corporate managers, others involve how corporate managers react to market inefficiencies.

I am going to close these remarks by going back in time, first a few decades, and then a few centuries. My first work as a behavioral economist began in the 1970 s with Richard Thaler, and involved the study of self-control. Thaler and I developed a dual system theory, in which a decision maker's choices emanate from the interaction between a subconscious automatic system involving emotions ("the doer") and a deliberative system involving conscious thought ("the planner"). Statman and I first applied this framework to the study of dividends, in our first behavioral work together.

With the publication of Kahneman's book Thinking, Fast and Slow, the System 1/System 2 framework is now recognized well outside the confines of academia. Kahneman identifies System 1 with intuition and System 2 with reason, which he links to the doer/planner dichotomy that Thaler and I developed. Although a few academics have pursued a formal two system approach to human decision making, my sense is that there is much untapped potential in applying this framework to study financial issues.

Behavioral economics did not begin in the 1970s. John Maynard Keynes was already writing extensively about the role of psychology in the 1930s. His famous treatise The General Theory of Employment, Interest, and Money uses the word "psychology" many times, and makes many references to "optimism," "confidence," and "sentiment." $\mathrm{He}$ is very clear about corporate managers failing to base decisions on computations of discounted cash flow, let alone probability assessments of alternative cash flows. Likewise, he emphasizes the role of sen- 
timent in driving the market prices of securities. Without question, Keynes was a behavioral economist.

The dual system perspective of decision making is centuries old. Adam Smith termed System 2 a person's “impartial spectator" and System 1 a person's "passion." Smith's focus was on moral behavior, especially in the market- place. Earlier this year, I wrote that Adam Smith would not have been surprised by the recent Libor fixing scandal. What has changed in the course of almost two and a half centuries is that behaviorally minded academics are developing psychologically-based insights into why people cheat.

A rich new line of inquiry has just begun involving collaborations between neuroscientists and economists. Future work will study the roles of brain structure, hormonal balance, and genetic traits on financial decisions and market outcomes. There is much to which we can look forward. It is an exciting time for those with a passion to understand how psychology impacts finance. 